\title{
The Use of Musculoskeletal Ultrasonography for Spinal Pains Among Athletes, Gaps in the Knowledge
}

\author{
Pardis Noormohammadpour ${ }^{1}$ and Navid Moghadam (iD) ${ }^{1, *}$ \\ ${ }^{1}$ Sports Medicine Research Center, Neuroscience Institute, Tehran University of Medical Sciences, Tehran, Iran \\ "Corresponding author: Sports Medicine Research Center, Neuroscience Institute, Tehran University of Medical Sciences, No. 7, Al-e Ahmad Highway, Tehran, Iran. Email: \\ Navid.mgd@gmail.com
}

Received 2019 July 07; Accepted 2019 August 02.

Keywords: Low Back Pain, Ultrasonography, Athletes

Researchers and clinicians use musculoskeletal ultrasonography for the evaluation of spine-related structures (transabdominal and paraspinal muscles) (1) and the rehabilitation of spinal pains (neck and low back pain) (2) in everyday practice. The use of musculoskeletal ultrasonography has been validated among groups with different physical profiles, including but not limited to obese patients (3), pregnant women (4), and patients with chronic neuropathy (5). It has been shown that musculoskeletal ultrasonography is a reliable tool for evaluation of spinal structures and progress of the rehabilitation of pains among these patient groups regardless of their physiologic profile and changes in the musculoskeletal system due to their condition.

There have been studies which have used musculoskeletal ultrasonography in athletes. It has been used in the evaluation of transabdominal and paraspinal muscles in adolescent (6) and young (7) soccer players with/without low back pain. Researchers have also tracked muscle changes with musculoskeletal ultrasonography among soccer players during a season with and without developing low back pain (8). However, these studies were not confined to soccer, there have been studies using musculoskeletal ultrasonography among cyclists (9) and recreational runners (10), cricket players (11). Gray et al. have shown that contrary to the non-athlete population, symmetry and non asymmetry, of transabdominal muscles is concurrent with low back pain in cricket bowlers (12).

These findings would emphasize on sport-specific considerations in using musculoskeletal ultrasonography for spinal pains such as the biomechanics of the sport, side dominancy of the athlete and ultrasonography of the sport-specific functions. It should also be considered that to the best knowledge of ours, there is no study using mus- culoskeletal ultrasonography for neck pain among athletes. These points can help to design future studies which will address the concerns of using musculoskeletal ultrasonography for athletes' spinal pains.

\section{Footnotes}

Conflict of Interests: It is not declared by the authors. Funding/Support: It is not declared by the authors.

\section{References}

1. Heidari P, Farahbakhsh F, Rostami M, Noormohammadpour P, Kordi $\mathrm{R}$. The role of ultrasound in diagnosis of the causes of low back pain: A review of the literature. Asian J Sports Med. 2015;6(1). e23803. doi: 10.5812/asjsm.23803. [PubMed: 25883773]. [PubMed Central: PMC4393543].

2. Noormohammadpour P, Kordi M, Mansournia MA, AkbariFakhrabadi M, Kordi R. The role of a multi-step core stability exercise program in the treatment of nurses with chronic low back pain: A single-blinded randomized controlled trial. Asian Spine J. 2018;12(3):490-502. doi: 10.4184/asj.2018.12.3.490. [PubMed: 29879777]. [PubMed Central: PMC6002169].

3. Noormohammadpour P, Kordi R, Dehghani S, Rostami M. The effect of abdominal resistance training and energy restricted diet on lateral abdominal muscles thickness of overweight and obese women. J Bodyw Mov Ther. 2012;16(3):344-50. doi: 10.1016/j.jbmt.2011.12.001. [PubMed: 22703744].

4. Rostami M, Noormohammadpour P, Mansournia MA, Hantoushzadeh S, Farahbakhsh F, Nourian R, et al. Comparison of the thickness of lateral abdominal muscles between pregnant women with and without low back pain. PM R. 2015;7(5):474-8. doi: 10.1016/j.pmrj.2014.10.014. [PubMed: 25459655].

5. Noormohammadpour P, Dehghani-Firouzabadi A, Mansournia MA, Mohseni-Bandpei MA, Moghaddam N, Miri M, et al. Comparison of the cross-sectional area of longus colli muscle between patients with cervical radicular pain and healthy controls. PM R. 2017;9(2):120-6. doi: 10.1016/j.pmrj.2016.06.020. [PubMed: 27346094]. 
6. Noormohammadpour P, Hosseini Khezri A, Linek P, Mansournia MA, Hassannejad A, Younesian A, et al. Comparison of lateral abdominal muscle thickness and cross sectional area of multifidus in adolescent soccer players with and without low back pain: A case control study. Asian J Sports Med. 2016;7(4). e38318. doi:10.5812/asjsm.38318. [PubMed: 28144414]. [PubMed Central: PMC5259683].

7. Noormohammadpour P, Mirzaei S, Moghadam N, Mansournia MA, Kordi R. Comparison of lateral abdominal muscle thickness in young male soccer players with and without low back pain. Int J Sports Phys Ther. 2019;14(2):273-81. [PubMed: 30997279]. [PubMed Central: PMC6449017].

8. Linek P, Noormohammadpour P, Mansournia MA, Wolny T, Sikora D. Morphological changes of the lateral abdominal muscles in adolescent soccer players with low back pain: A prospective cohort study. Journal of Sport and Health Science. 2018;In Press. doi: 10.1016/j.jshs.2018.02.002.

9. Rostami M, Ansari M, Noormohammadpour P, Mansournia MA, Ko- rdi R. Ultrasound assessment of trunk muscles and back flexibility, strength and endurance in off-road cyclists with and without low back pain. J Back Musculoskelet Rehabil. 2015;28(4):635-44. doi 10.3233/BMR-140559. [PubMed: 25391328].

10. Cai C, Kong PW. Low back and lower-limb muscle performance in male and female recreational runners with chronic low back pain. J Orthop Sports Phys Ther. 2015;45(6):436-43. doi: 10.2519/jospt.2015.5460. [PubMed: 25899213].

11. Hides JA, Stanton WR, McMahon S, Sims K, Richardson CA. Effect of stabilization training on multifidus muscle cross-sectional area among young elite cricketers with low back pain. J Orthop Sports Phys Ther 2008;38(3):101-8. doi: 10.2519/jospt.2008.2658. [PubMed: 18349481].

12. Gray J, Aginsky KD, Derman W, Vaughan CL, Hodges PW. Symmetry, not asymmetry, of abdominal muscle morphology is associated with low back pain in cricket fast bowlers. J Sci Med Sport. 2016;19(3):222-6. doi:10.1016/j.jsams.2015.04.009. [PubMed: 26059231]. 